\title{
TRANSITION OFFENSE IN TOP-LEVEL EUROPEAN BASKETBALL
}

\author{
Mario Jeličić \\ Faculty of Kinesiology, University of Split, Split, Croatia
}

Original scientific paper

\begin{abstract}
Purpose: The purpose of this study was to determine differences in the use of transition pick and roll/pop and transition post-up maneuvers in two top teams from the EuroLeague basketball (first placed and ninth placed teams in the 2019/2020 season). Methods. The sample of respondents consisted of 56 EuroLeague basketball games played by teams Anadolu Efes Istanbul (28) and Zalgiris Kaunas (28), the ANA team and the ZALAG team respectively. Variables for estimating transition offenses were collected during EuroLeague senior basketball matches. A total of 16 variables (Toff_tot, TP\&R/P_tot, TP\&R/P_suc, TP\&R/P_uns, \%suc P\&R/P, \%uns P\&R/P, TP_up_tot, TP_up_suc, P_up_uns, \%suc P_up, \%uns_P_up, TO, \% TO, Toff_point, TP\&R/P_point; and Tpup_point) were assessed to estimate transitional offenses in teams that use early pick and post-up maneuvers in their performance. Results. Findings showed statistically significant differences between two analyzed teams in variables as described further in the text. The ANA team performed less TP \& R/P_tot offenses per game then the ZALG team. Also, when it comes to the total number of transition post-up situations, the ANA performed less of these then the ZALG per game. At the end, the ANA team lost on average less balls than the ZALG team per game in the Transition offense. Conclusions. Obtained differences that occurred between two analyzed basketball teams cannot fully explain placement of the teams in the table. The main difference comes from the philosophy of the coach and the very concept of the team or individual quality of the players.

Key words: top European basketball transition offense, transition pick \& roll/pop, transition post-up
\end{abstract}

\section{INTRODUCTION}

Modern basketball, from the point of view of technical and tactical aspects of the game, is a complex team sport dominated by quick transitions. Transition offense is one of the offensive strategies used frequently in basketball with two basic conditions, position 1 and transition 2 (Trninić, Perica, Pavičić, 1994). The position state can be divided into phases of set defense and set offense and equally, the transition state can be divided into phase transition defense and phase transition offense. In a typical transition offense, the defense team comes into possession of the ball and tries to confirm the fastest player within their team. This is usually the player who plays the position of organizer of the game, who seeks to pass the ball to the other half of the court as soon as possible and to confirm one of the two wing players accompanying it in that counter offense on easy layup. If there is no easy point scored by the wing player, the organizer of the game can also make shot to the basket. In any case, the speed of recognizing the situation in the game, the speed of action, leadership and passing the ball, are the most important factors of a successful transition offense. It is important to emphasize, however, that in a basketball game there is no exclusive orientation of each team to play fastbreak offense. This is because fastbreak is the result of a primarily good game in the defense of a single team, so most of these offenses result from a missed shot by the opponent (jump in defense) and a deflected dribble or passing line. The progress of modern basketball is also reflected in the streamlining of movement structure and structure of situations performance associated with new rules in the game. In today's modern basketball, many authors agree that a transition offense consists of a transition state as a whole (primary and secondary offense) or a transition and positional state where the positional state lasts much shorter than the transition state (early offense) according to Selmanović et al. (2015). In order to characterize the offense as a transition, it is necessary to satisfy the criterion of winning the ball in the defensive field of the basketball court, followed by the transition and the end of the offense. If the ball is won in the offensive field of the basketball court and a quick realization is achieved, the offense is classified in the category of "other offenses" (Selmanović et al., 2015). It is also important to write down that the concept of transition implies the transfer of the entire player plus ball system from the defense phase to the offensive phase, without limiting this notion to the movement of the ball alone or to the movement of the player only (Trninić, Perica, Pavičić, 1994). According to the above, transitional offenses are classified into 
three types of offense: 1) primary transition offense consists solely of the transition state and a situation is created in the end zone of the offense, involving up to 2 defensive players (situations 1:0, $2: 1,3: 1,1: 1,2: 2$ and $3: 2) ; 2$ ) secondary transition offense consists solely of a transition state and a situation is created in the zone of the offense ending in which 3 or 4 defensive players participate (situations 3:3, 4:3, 5:3, and 5:4); 3) early offense is an offense that, in addition to the transition state, contains a positional state where in the duration of the positional state generally lasts shorter than transition state (tps <tts). As a rule, it is a 5 on 5 setting in the end zone, this offense can also be unambiguously determined as a transition offense in 5 on 5 situations. In addition to the content of the position state, early offense is distinguished from a primary and secondary offense by preferably reading the tactical completion of the offense. In this work, as in a large number of studies, early offenses are classified as transition offenses, although as such they can also be characterized as a special type of basic offense. Because of the subject and the problem of this work, the research so far has been divided. In the field of kinesiological research, the scientific approach to the analysis of transition offense in the basketball game can be classified in several directions (Trninić et al. 1994., Tsamourtzis, Karipidis \& Athanasiou (2005), Fotinakis, Karipidis \& Taxildaris (2002), Selmanovic et al. (2015): research on the structure of the basketball game, the state of the basketball game and studies that addressed the structure of different types of transition offense and their effect on basketball performance.

The characteristics of the transition offense, its beginning, its course and its ending were analyzed by Sanchez, Courel, Estevez, Ortega, Pinar \& Cardenas (2012), based on 169 FIBA EuroBasket transition offenses in 2009. They found that the winning teams had a higher success rate of transitions (54.1\% vs. $45.9 \%)$, which was consequently significantly reflected in the higher overall share of points earned. The authors emphasized the importance of securing a defensive rebound, which generated the largest number of fastbreaks. Other features that affected a successful implementation were evident in actions that included a "double pass" and those with no more than two passes. Garefis, Tsitskaris, Mexas \& Kyriakou (2007) compared the structure of transition offense between the Greek Championship and the EuroLeague where they concluded that there was no significant difference in transitional offense between them. Results showed a significantly higher num- ber of situations 4 to 3 in the Greek Championship $(13.8 \%)$ and 1 to 1 in the EuroLeague competition $(14.3 \%)$. In the segment of success of realization of certain settings of numerical superiority of the striker, a significantly higher performance was found in the situation 4 to 2 within the Greek Championship - the success rate was $91.4 \%$ as opposed to $67.4 \%$ in the EuroLeague basketball. So, realizations within the zone of three points and additional training on those settings of primary and secondary transition offenses that proved ineffective by the research should be looked at more carefully.

Tsamourtzis, Karipidis \& Athanasiou (2005) analyzed the commitment and impact of transition offense on the 26-games sample in different Championships organized by FIBA from 20022004 where it was confirmed that three on two offenses showed no difference between the winning and losing teams, nor were these the most common situations in the game. Similar theses were previously established in the work of Fotinakis, Karipidis \& Taxildaris (2002) in which, based on 31 matches of the European Championships (France, 1999), they studied the factors that characterized the transition offenses in European basketball. The results confirmed situation 3-2 as the most common model of transition offense and added that transitions were most often initiated after a defensive rebound and that the initial addition significantly affected the development of the action. The primary transition offense was realized mainly between 3 and 9 seconds, and the secondary between 6 and 12 seconds. Research of these authors did not confirm the significance of differences in the use of transitional offenses that would result in the victory or defeat of an individual team. Selmanović et al. (2015) described offensive categories in basketball game which were set in the most precise way possible and with an accurate explanation of the interpretation which was in harmony with the type and duration of action. The author discovered that in elite basketball $15-20 \%$ of all offenses are transitional (primary, secondary and early) and that their positive efficiency amounts 48 - 51\%, which leads us to the conclusion about the importance of using them during the training process and during games.

In general, in a basketball game, specific cooperation and communication that derives from motor activity includes the movement of players without the ball and the flow of basketball. The structure of the transition offense in basketball situation is characterized by preparation of the offense phase, the central phase of the offense 
and the final phase of the offense. The task of tactical preparation is the adoption and improvement of individual, group and collective tactics of both offense and defense. Building a transition offense in order includes tasks that focus on individual (such as attacking, opening), group (cooperation of two, three players) and collective tactics. The effectiveness achieved by any type of transition offense depends on many factors. The strategy and tactics of winning tactics in practice is determined on the basis of information about qualities of our players or possibilities of opposing teams, which is limited by the status of anthropological characteristics (motor, anthropometric, functional, specific cognitive abilities - tactical thinking abilities, tactical thinking speed, also in the level of adoption, usability and automation of movement structures that make up the actual content of each situation or strategy in basketball games. The success of transition offense on one team largely depends on the success of good play in defense, boxing out, rebounding, passing, filling lines of movement, running screening, posting up in transition offense and finishing to the basket. In modern basketball, almost all players' behavior is learned, which is probably why almost all basketball is based on scientific grounds as a game.

The aim of this study is to provide an overview of differences between types of transition offenses and attempts to contribute to a more precise understanding of the size and importance of the influence of styles of play in the transition offense (pick \& roll and post up maneuvers) by the defined criteria on the number of points achieved. Studying the structural specificities of different understandings of transition offense allows for a constructive interpretation of basketball game events that can be useful in coaching and professional practice in terms of their significant impact in achieving certain results. Present study aimed to determine differences in the use of transition pick and roll / pop and transition post up maneuvers in two top teams in the 2019-2020 EuroLeague season (first placed EuroLeague team and ninth placed team). So, the first hypothesis was that there would be no distinction in the use of the transition pick and roll, transition pick and pop and transition post-up maneuvers between those two high quality Euro League teams. Secondly, the differences in the use of transition offense pick \& roll/pop and post-up maneuvers would not impact the final standings.

\section{METHODS \\ Participants}

The sample of respondents (entities) consisted of 56 EuroLeague basketball games played by teams Anadolu Efes Istanbul (28) and Zalgiris Kaunas (28) in the 2019/2020 season. Complete sample of the variables was obtained by the notational analysis of transition pick and roll/pop and transition post-up situations identified and recorded from clips taken from the Synergy Sports software.

The variables for estimating transition offenses were collected at EuroLeague senior basketball matches in 2019/2020 season. A total of 16 variables were assessed to estimate transition offenses that use early pick and post-up maneuvers in their performance; Toff_tot; transition offense total, TP\&R/P_tot; transition pick and roll/pop total, TP\&R/P_suc; transition pick and roll/pop, TP\&R/P_uns; transition pick and roll/pop unsuccessful, \%suc P\&R/P; \% successful pick and roll/pop, \%uns P\&R/P; \% unsuccessful pick and roll/pop, TP_up_tot; transition post- up total, TP_up_suc; transition post-up successful, P_up_uns; transition post- up unsuccessful, \%suc P_up; \% successful post- up, \%uns_P_up; \% unsuccessful post- up, TO; turnovers, $\%$ TO; $\%$ turnovers, Toff_point; transition offense points, TP\&R/P_point; transition pick and roll/pop points and TP up point; transition post-up points.

Two criteria for selection of analyzed situations in this research were: 1) Transition pick \& roll/pop situations; this variable represented the number of transition pick and roll/pop offenses defined as those consisting of primary, secondary or early offenses, i.e. that take place in a continuous forward running motion using early pick and roll/pop maneuver and attacking the basket at the same time. It must be realized up to a maximum of fifteen seconds of offense and 2) Transition postup situations; this variable represented the number of transition post-up offenses defined as those made up of primary, secondary or early offenses, i.e. that take place in a continuous forward running motion using post up maneuver and attacking the basket at the same time. It must be realized up to a maximum of fifteen seconds of offense. Further, there were two possible endings of transition pick and roll/pop situations with associated criteria;

1) Successful transition pick and roll/pop situations and successful transition postup situations - defined as those situations in which a point was scored, or a personal foul was made in defense.

2) Unsuccessful transition pick and roll/pop situations and unsuccessful tran- 
sition post-up situations - defined as those situations in which the shot was missed, turnover (TO) was made or defense stopped transition offense by coming into ball possession or force offensive team to start playing set offense.

\section{Design}

PHASE 1 - within each previously mentioned game, by direct observation and analysis of each of the required offense, certain states of the transition offenses in basketball were identified. Variables were collected to estimate the frequency of transition pick and roll/pop and transition post-up situations, which were then recorded in the matrix for their processing. Variables for the assessment of these situations as components of the transition offense were collected using the Synergy Sports software system for the 2019/2020 competition season.

PHASE 2 - processing and interpreting results; collected results were processed by appropriate statistical-mathematical procedures, followed by interpretation.
Statistical data processing was performed with the statistical package Statistics ver. 13th. The T-test for independent samples was used. In order to show the distinction between the elite and the average EuroLeague teams and to examine the statistical significance of differences in the use of these two situation structures between elite and average EuroLeague teams.

\section{RESULTS}

Basic descriptive features of the transition pick and roll/pop and transition post-up offenses of the Anadolu Efes and Zalgiris Kaunas EuroLeague professional basketball teams are displayed in Table 1.

The T-test; grouping variables Anadolu Efes (ANA) and Zalgiris Kaunas (ZALG), arithmetic mean (Mean), standard deviation (Std. Dev.), the value of $t$ of the test (t-value), degrees of freedom (df) and significance of differences ( $p$ ) of 16 assessed variables for exploring transition offenses that use early pick and post-up maneuvers in their performance are shown in Table 2.

Table 1. Basic descriptive features of the transition pick and roll/pop and transition post-up offenses of the Anadolu Efes and Zalgiris Kaunas EuroLeague professional basketball teams

\begin{tabular}{|l|c|c|}
\hline & Anadolu Efes & Zalgiris Kaunas \\
\hline Number of analyzed games & 28 & 361 \\
\hline Number of transition offenses - total & 313 & 159 \\
\hline $\begin{array}{l}\text { Number of transition pick and roll/pop } \\
\text { offenses - total }\end{array}$ & 119 & 42 \\
\hline $\begin{array}{l}\text { Number of transition post-up offenses - } \\
\text { total }\end{array}$ & 21 & 416 \\
\hline Number of points - total & 404 & 192 \\
\hline $\begin{array}{l}\text { Number of transition pick and roll/pop } \\
\text { points - total }\end{array}$ & 161 & 39 \\
\hline Number of transition post-up points - total & 19 & \\
\hline
\end{tabular}

A glance into the basic characteristics of the transition offense shows from Table 1 that the Euro League team ANA made a total of 313 transition offenses in 28 games, while the team of ZALG made 361 transition offenses in 28 games and in both situations (ANA \& ZALG); based on early pick and transition post-up. Further on, the ANA team played a total of 119 transition pick and roll/pop offenses and a Total of 21 transition post-up offenses while Zalgiris had 159 TP\&R/P tot and 42 TP up tot.

Analysis of the differences in the use of transition pick and roll/pop and transition post-up situations between the Anadolu Efes and Zalgiris Kaunas
EuroLeague basketball teams are shown in Table 2. It can be seen that in analyzed games there were a total of 28 transition pick and roll/pop as well as transition post-up situations. From those 28 situations/games, 11.2 on average per game were related to the Anadolu Efes team (hereinafter the ANA) while 12.9 of those offenses to the Zalgiris team (hereinafter the ZALG). In addition, it resulted that the ANA team performed 4.25 T P \& R/P_tot offenses (out of which 2.5 were successful and 1.8 unsuccessful) per game, while the ZALG team achieved a total of 5.7 T P \& R/P_tot offenses (out of which 3.2 were successful and 2.9 unsuccessful). 
Table 2. T-test; Anadolu Efes (ANA), Zalgiris Kaunas (ZALG), arithmetic mean (Mean), standard deviation (Std. Dev.), the value of $t$ of the test (t-value), degrees of freedom (df), significance of differences ( $p)$, significance of differences $(p)$

\begin{tabular}{|l|r|r|r|r|r|r|c|}
\hline & \multicolumn{2}{|c|}{ ANA } & \multicolumn{2}{c|}{ ZALG } & & \\
\hline & Mean & Std.Dev. & Mean & Std.Dev. & t-value & df & $\mathrm{p}$ \\
\hline Toff_tot & 11,17857 & 3,00683 & 12,89286 & 4,39983 & $-1,70219$ & 54 & 0,094471 \\
\hline TP\&R/P_tot & 4,25000 & 1,62447 & 5,67857 & 2,91933 & $-2,26267$ & 54 & 0,027701 \\
\hline TP\&R/P_suc & 2,46429 & 1,42678 & 3,18519 & 1,88184 & $-1,60464$ & 53 & 0,114517 \\
\hline TP\&R/P_uns & 1,78571 & 1,13389 & 2,92000 & 1,77764 & $-2,79982$ & 51 & 0,007203 \\
\hline \%suc P\&R/P & 58,03571 & 25,73401 & 53,05697 & 25,86312 & 0,72208 & 54 & 0,473359 \\
\hline \%uns P\&R/P & 41,96429 & 25,73401 & 43,37160 & 25,16007 & $-0,20691$ & 54 & 0,836855 \\
\hline TP_up_tot & 1,31250 & 0,79320 & 2,00000 & 1,14018 & $-2,05894$ & 35 & 0,047002 \\
\hline TP_up_suc & 1,12500 & 0,83452 & 1,58333 & 0,79296 & $-1,24065$ & 18 & 0,230662 \\
\hline P_up_uns & 1,09091 & 0,30151 & 1,64286 & 0,84190 & $-2,06486$ & 23 & 0,050389 \\
\hline \%suc P_up & 39,06250 & 47,40671 & 46,42857 & 45,91443 & $-0,47675$ & 35 & 0,636501 \\
\hline \%uns_P_up & 60,93750 & 47,40671 & 53,57143 & 45,91443 & 0,47675 & 35 & 0,636501 \\
\hline TO & 1,38889 & 0,69780 & 1,80000 & 1,22927 & $-1,13632$ & 26 & 0,266187 \\
\hline \% TO & 8,60225 & 3,65768 & 14,43021 & 7,35088 & $-2,82024$ & 26 & 0,009063 \\
\hline Toff_point & 14,42857 & 5,05106 & 14,85714 & 6,55865 & $-0,27395$ & 54 & 0,785171 \\
\hline TP\&R/P_point & 5,75000 & 3,27307 & 6,85714 & 4,44484 & $-1,06133$ & 54 & 0,293265 \\
\hline Tpup_point & 2,71429 & 1,88982 & 3,25000 & 1,91288 & $-0,59136$ & 17 & 0,562060 \\
\hline
\end{tabular}

Legend; ANA; Anadolu Efes Istanbul, ZAL; Zalgiris Kaunas, Toff_tot; transition offense total, TP\&R/P_tot; transition pick and roll/pop total, TP\&R/P_suc; transition pick and roll/pop successful, TP\&R/P_uns; transition pick and roll/pop unsuccessful, \%suc P\&R/P; \% successful pick and roll/pop, \%uns P\&R/P; \% unsuccessful pick and roll/pop, TP_up_tot; transition post-up total, TP_up_suc; transition post-up successful, P_up_uns; transition post-up unsuccessful, \%suc P_up; \% successful post-up, \%uns_P_up; \% unsuccessful post-up, TO; turnovers, \% TO; \% turnovers, Toff_point; transition offense points, TP\&R/P_point; transition pick and roll/pop points, TP up point; transition post-up points

In percentages, the ANA team had $58 \%$ successful and $42 \%$ unsuccessful $P$ \& R/P situations in transition while the ZALG team had $53 \%$ successful and $43 \%$ unsuccessful $P$ \& R/P situations in transition. Also, when considering the total number of transition post-up situations, the ANA averaged 1.31 (out of which 1.13 were successful and 1.09 unsuccessful) while the ZALG had 2.0 per game (out of which 1.58 were successful and 1.64 unsuccessful). In percentages, the ANA team had $39 \%$ successful and $61 \%$ unsuccessful P_up situations in transition while the ZALG team had $46 \%$ successful and $53.6 \%$ unsuccessful P_up situations in transition. When it comes to the lost balls (turnover - TO) in the transition offense, the ANA team had 1.4 (8.6\%), while the ZALG team had $1.8(14.43 \%)$, average per game. On average, the ANA team scored a total of 14.4 points per game from these two situations in the transition offense, out of which 5.75 from T P \& R/P and 2.7 from T P_up. On the other hand, as shown in Table 2, the ZALG team averaged 14.85 points per game from these two situations in the transition offense, out of which 6.85 from $T P \& R / P$ and 3.25 from T P_up. Table 2 shows the stated representation of the analyzed variables of these two clubs.

\section{Comparison between won and lost games}

Figures from $1 \mathrm{a}$ and $1 \mathrm{~b}$ to $7 \mathrm{a}$ and $7 \mathrm{~b}$ show $\mathrm{a}$ comparison between winning and losing teams in the variables discussed in this paper.

In games that ended with victory, there were a higher total number of transition offenses compared to the teams that lost matches.

The frequency histogram in Figure 2a and Figure $2 b$, indicates that losing teams had a significantly lower frequency of the overall use of P\&R situations than the winning ones. 
Figure $1 \mathrm{a}$ and $1 \mathrm{~b}$ - Comparison between won and lost games for transition offense total

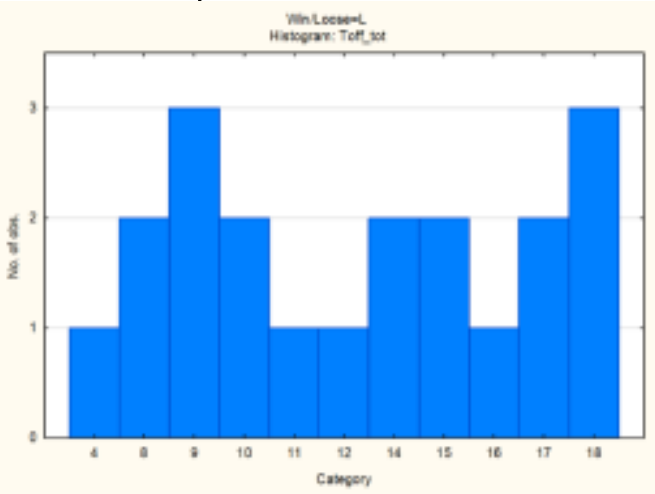

Figure 1 a.

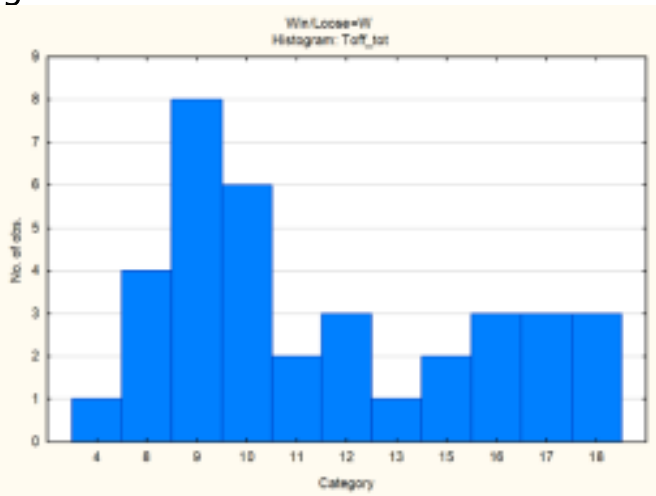

Figure $1 \mathrm{~b}$

Figure $2 \mathrm{a}$ and $2 \mathrm{~b}$ - Comparison between won and lost games for transition pick and roll/pop total

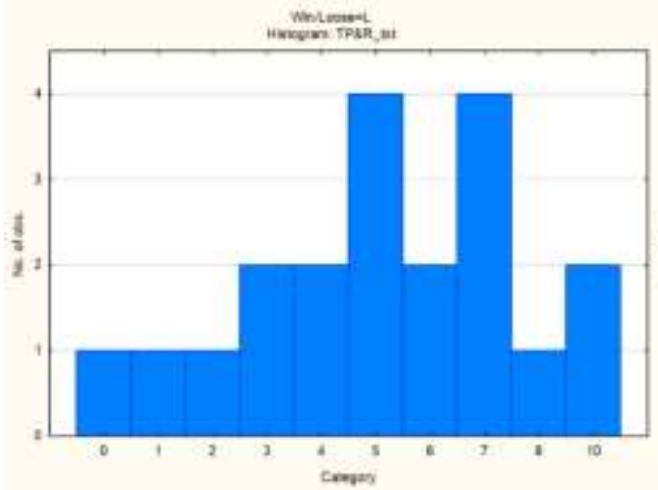

Figure $2 a$

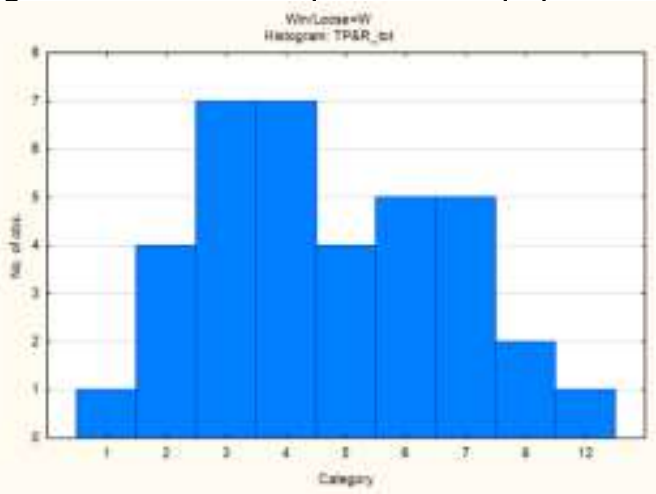

Figure $2 b$

Figure $3 \mathrm{a}$ and $3 \mathrm{~b}$ - Comparison between won and lost games for transition pick and roll/pop successful

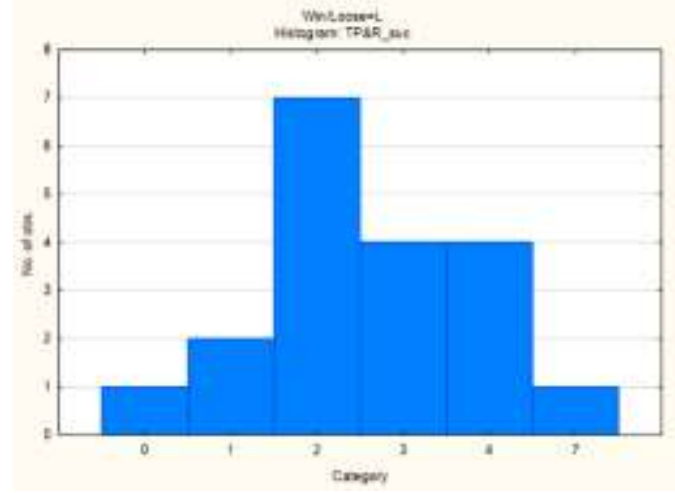

Figure $3 a$

When it comes to successful endings in transition P\&R situations, it can be seen that winning teams

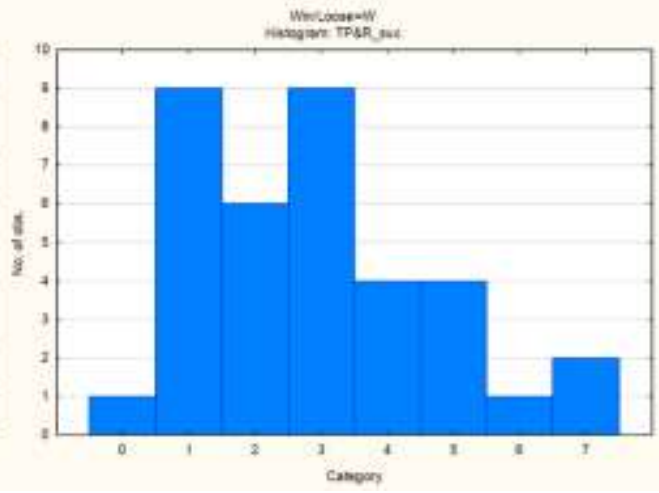

Figure $3 b$

had a lot more of these than the teams that lost their games. 
Figure $4 \mathrm{a}$ and $4 \mathrm{~b}$ - Comparison between won and lost games for transition pick and roll/pop unsuccessful

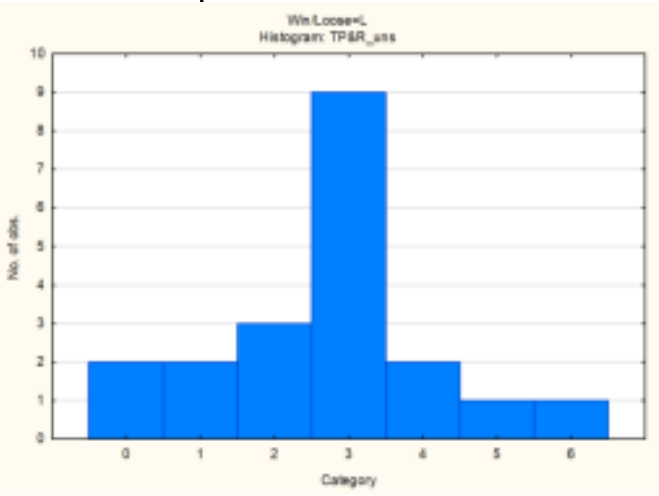

Figure $4 a$

Contrary to the previous histogram, it can be seen, histograms $4 a$ and $4 b$, here that losing

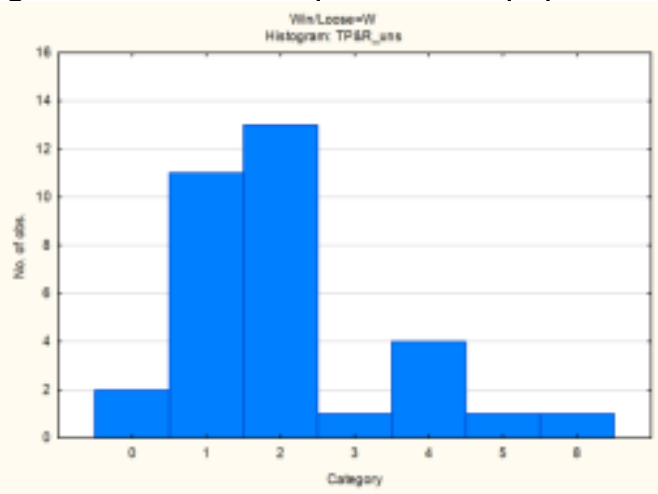

Figure $4 b$

teams had a higher number of unsuccessful transition $\mathrm{P} \& \mathrm{R}$ realizations.

Figure $5 \mathrm{a}$ and $5 \mathrm{~b}$ Comparison between won and lost games for transition post-up total

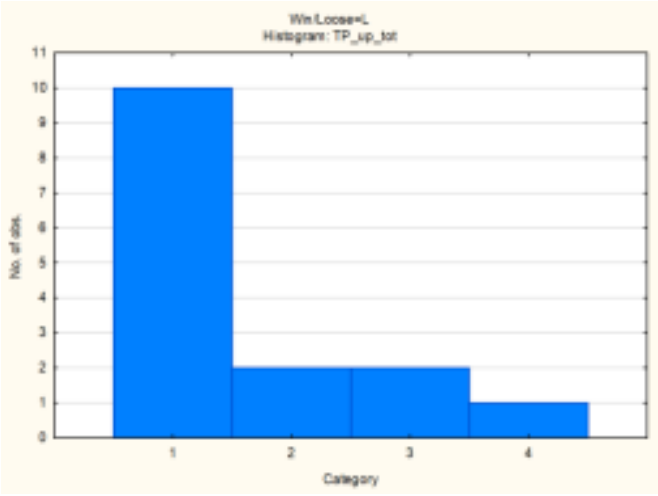

Figure $5 a$

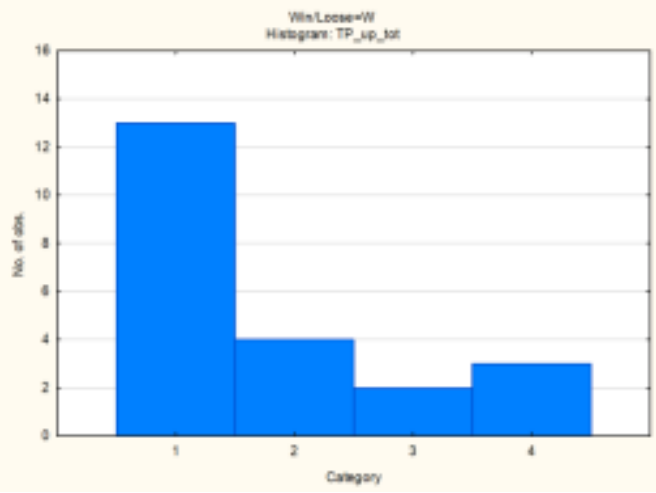

Figure $5 b$

Histograms $5 a$ and $5 b$ indicate that winning teams had a slightly higher number of transition post-up maneuvers than losing teams.

Figure $6 \mathrm{a}$ and $6 \mathrm{~b}$ Comparison between won and lost games for transition post-up successful

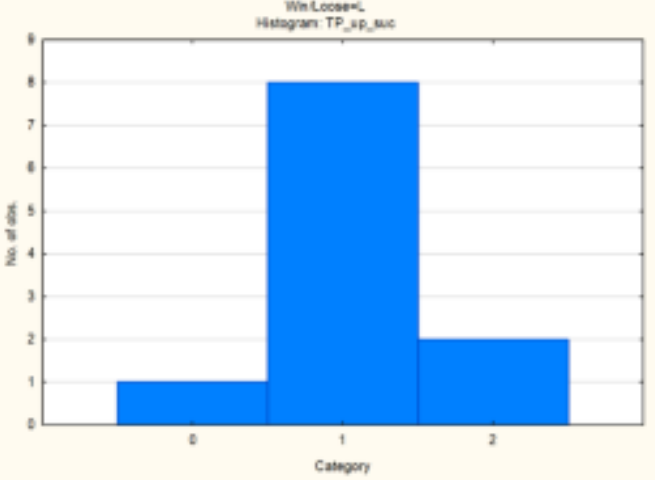

Figure 6a

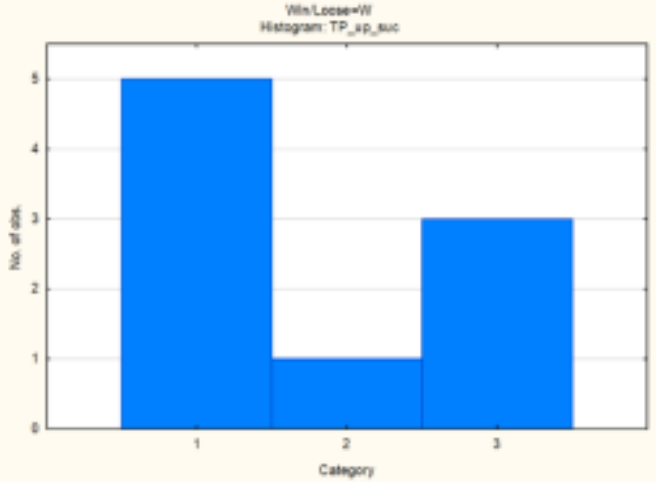

Figure $6 b$

Histograms $6 a$ and $6 b$ indicate an equal frequency of events among winning and losing teams in the

use of transition post-up maneuvers that ended in a successful outcome. 
Figure 7a and 7b Comparison between won and lost games for transition post-up unsuccessful

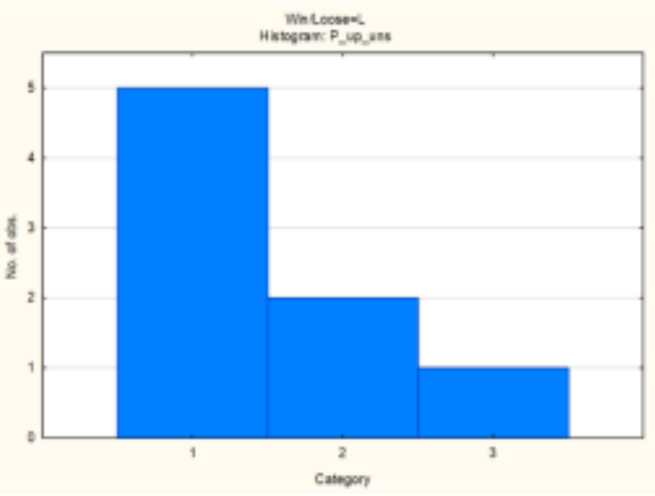

Figure $7 a$

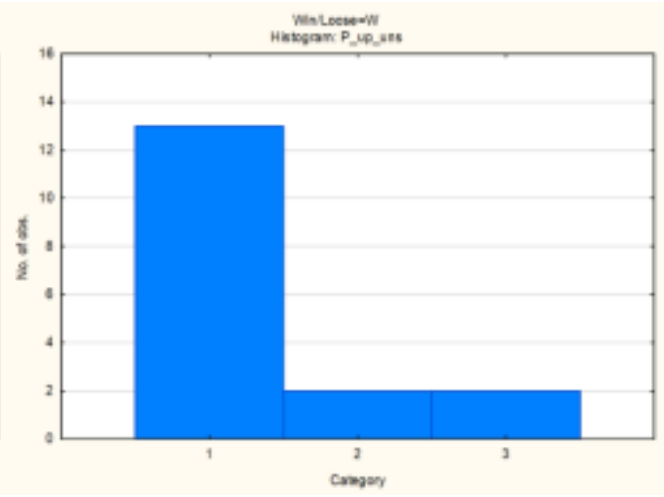

Figure $7 b$

There is no significant difference between winning and losing teams in unsuccessful transition postup maneuver performances.

\section{DISCUSSION}

Current study will try to clarify 4 statistically significant differences that occurred among the analyzed variables as well as other variables that are interesting for interpretation, although there were no statistically significant differences between them. First significant difference can be seen in Table 2 regarding the transition pick \& roll/pop variable as follows: the ANA team-4.25 per game and the ZALG team-5.67 per game. The assumption is that the above statistically significant difference is higher in the ZALG team compared to the ANA team due to the concept of the game and the composition of the ZALG team whose game was much more focused on playing transition offenses or early pick in transition.

In terms of efficiency, the percentages are approximately the same. The Anadolu Efes team had $58 \%$ of successful pick \& roll/pop situations while the Zalgiris team had $53 \%$ of successful pick \& roll/pop situations in the season. The ANA team used early pick in a significantly higher proportion than the ZALG team, in which due to the individual quality of the players, such concept was played more (more pick and pop situations because of tall players with excellent shooting abilities). Thus, they simply have good positions for an open shot and the option of having a high percentage of realization. Because of their individual quality (shooting range) these players have good spacing, they pop-out well, and from that width they have a lot of open shots. The ANA obviously lacked in individual quality of this kind and they did not use those situations as much (less pick situations in transition and less post ups).

This is mostly because they had great individuals which played more with ball. First of all, Larkin, because of his individual quality (very dominant in 1-on-1 game), he created advantage and options to score with good percentage in transition for himself as well as for his teammates. He simply used his speed and good technique (skill). For example, when he got into the possession of the ball at half of the backcourt, he was able to pass by four defensive players and make layup by himself. They had no time to make a pick because he was already on the layup or got some foul etc. It was really hard to hold him 1-on-1 without extra help. The defense often had to organize to defend him, which means at least 1 more player needed to help. So, there would be an option of an outside pass for spot up shoot or penetration, but there was no much $P \& R^{\prime} s$, and also not much post-up game. Another variable in which these two teams differed significantly is unsuccessful transition $P \& R / P$. The ANA had less statistically significant mistakes compared to the ZALG. The total of 1.78 for the ANA compared to 2.92 for the ZALG, which can be explained with the fact that the ANA primarily played less T P \& $R$ and $T$ P-up than the ZALG, and therefore had less opportunities to make an error. Percentage of realization was similar (58\% the ANA and $53 \%$ the ZALG). Thus, the ZALG played more pick \& pop and the ANA maybe played more pick \& roll, so from pick \& roll situations there would be more options for fouls, free-throws, etc. which are considered as successful situations. The third variable in which these two teams differed significantly is T P up total, namely 1.31 average for the ANA and 2.00 average for the ZALG. This 
difference again primarily depends on the player profile, but also on the general tendency that there are no more very dominant centers, so there is not much tendency to play post-up in transition. Also, from the team profile it can be concluded that the ZALG had generally more players for post-up play than the ANA. As it was previously mentioned, this is partly due to the profile of players within a particular team (the ANA had no dominant players in the post-up position - or in any position compared to the ZALG) but also, the team philosophy of the game was different. Therefore, the ZALG dropped the ball a bit more to the low post even though the tendency of basketball today is not to play a lot of classic postup. There are no more dominant centers as before as well, and there are more polyvalent players, so we have more switching. It means that there is no longer big advantage in the strength and height of the players. This is certainly one of the reasons that post-up is no longer being forced. It had more benefits in the past, but today not as much. A player goes on the low post position, for example, but defense switch and the player is guarded on that low post position by someone with similar height and weight or even skills, and it is difficult to get advantage out of post-up play. Thus, there is no sense to force this. Considering that the ZALG played for 17\% (50) more transitions than the ANA, it can be said that the coach's philosophy was to force more transition game or style with bigger pressure in defense, which is a basic presumption for that kind of play. The fourth significant difference between these two teams is in the variable \% TO, namely 8.6 for the ANA in relation to 14.3 lost balls for the ZALG transition offense based on early pick and post up. This also confirms the thesis that the coach of ZALG forced fast play regardless if they made a few errors more and that was simply the coach's philosophy. Although, no significant differences were found between those two teams in transition off total (11.2 for the ANA; 313:28, compared to for the 12.9 ZALG) that would confirm the thesis that the ZALG coach had a tendency of fast transition game. The variable T P \& R success, which also shows no statistically significant differences, indicates that their effectiveness was approximately the same. In other words, the ZALG had a higher total number, but the realization was approximately the same, while the ANA had a bit higher percentage. The percentage of successful P \& R shows no statistical significance, but there is an obvious difference, $58 \%$ for the ANA versus 53\% for the ZALG which can be explained in greater use of $P \& R$ maneuvers by the ANA compared to the ZALG which used more P\&P. Basically, it can be concluded that the difference is in coaching philosophy and individual quality of the players (some better shooters are more based on pop out situations and the others on roll). As far as T P-up success is concerned, the ZALG had a slightly higher number of successful P-up maneuvers in transition (1.125 for the ANA compared to 1.58 for the $Z A L G)$. The reason is more players from the ZALG team having individual characteristics to play P-up, and it made more sense. As a result, they were more successful in the mentioned variable at the very limit of statistical significance (0.0503) which can potentially indicate that the ZALG coach favored the transition game while the ANA did not force transition at all. The ZALG would set offense and then it would become an unsuccessful transition while the ANA did not even try to play the transition, and therefore had no unsuccessful attempts, according to our criteria. The ANA tried to play the transition less time, so they were unsuccessful less times. There is no deviation here in the percentage - the ZALG was better than the ANA. Deviations are only found in in unsuccessful attempts, and only because the way the criteria was set. Also, because of the style of the game, the resulting numbers are as such. Since the ANA did not play the transition much, it is logical that they had less unsuccessful attempts. The ZALG, on the other hand, tried to play transition due to the coach's philosophy, though without success, and they played a set offense after transition but, according to our criteria, it was an unsuccessful $T$ offense. We can say that the ANA's tactics were better than the ZALG's situations. The ANA had a better selection between players who performed better certain tactical maneuvers. As stated, the ZALG played a bit more post-up because of the concept of the game and because they had more players able to play good post-up game, there is no logic that the ANA was more successful in that either. It can be simply concluded that they played with bigger discipline and chose better situations (for example, they had a better selection of shots and they shot from more certain positions). Thus, they did not play a lot of post-ups because they had no adequate players for that, but when they played it, they played in a better way and they just had a better realization. Results show that $39 \%$ of T P_up situations were successful for the ANA and $46 \%$ for the ZALG, while $60 \%$ of unsuccessful post-up for the ANA compared to $53.6 \%$ for the ZALG, which is logical. The ZALG had a better realization in $\mathrm{T} P$ up because they had players for that kind of game situations and played more of 
these. The ANA did not have players for transition post-up plays and they were worse in realization. Therefore, they had a higher percentage of failures. Furthermore, results show differences between the ANA and EFES in TO (1.38 for the ANA in relation to 1.8 for the $Z A L G$ ) but with not statistically significant difference. Things are different with \% TO where there is a statistically significant difference between two named teams (namely 8.6 for the ANA in relation to 14.4 for the ZALG). It can be said that the ANA team did a better selection of when they got into transition post-up maneuver. The Zalgiris team insisted on a transition game at the cost of a mistake, thus more errors occurred (TO). T off points, 14.4 for the ANA compared to 14.85 for the ZALG, are almost equal. There is no difference in the points scored compared in relation to the previous differences, perhaps because of individual quality and better individual solutions, i.e. the selection of shots and the offense. These better percentages of realization came from less transition offenses which resulted in approximately the same numbers. Points in $T P \& R$ (5.75 for the ANA team vs. 6.86 for the ZALG team) and points in $T$ P-up (2.71 for the ANA vs. 3.25 for the ZALG team). The reason for this is coaching philosophy and thus a larger number of points scored from those situations.

When it comes to comparisons between matches that ended in victory or defeat in the variables investigated in this paper, it can be concluded as follows.

The higher total number of occurrences of transition offenses in winning teams compared to losing teams (Figures $1 \mathrm{a}$ and $1 \mathrm{~b}$ ) is in line with the previous scientific research and practice. Namely, the previous research has shown that at the level of EuroLeague or NBA competition, transition offenses represent an average of $18.5 \%$ of the total number of offenses. Out of these previously mentioned, $51.8 \%$ in average are successful (Jelaska, 2011; Selmanović, 2015). This tells us about its high representation and high percentage of success in matches of the highest quality and thus the distinction between winning and losing teams.

Furthermore, losing teams had a significantly lower frequency of the overall use of $P \& R$ situations than the winning ones (Figure $2 a$ and Figure 2b), which is interesting from the aspect of practice because it indicates the importance of practicing transition $P \& R$ in training and its application in matches. Of course, it is necessary to emphasize and consider the quality of players that each team has in order for the success of these actions to be consequently important for their success in the game.

Likewise, winning teams have a higher number of successful finishes in transition P\&R situations than losing teams (Figures $3 a$ and $3 b$ ), which is understandable given that these are mostly simple finishes that often, among other things, demoralize opposing players.

Accordingly, losing teams have a higher number of unsuccessful transition P\&R realizations (Figures $4 a$ and $4 b$ ). When it comes to the frequency of use of transition post-up maneuvers (Figures $5 \mathrm{a}$ and $5 b)$, it can be noticed that there was a minor difference between winning and losing teams (in favor of winning teams), which can be explained in the somewhat less frequent use of this activity in elite basketball and because of slightly more quality centers when they play in the low or middle low post position.

Almost equal frequency of events between winning and losing teams in the use of a transition post-up maneuver that ended in a successful outcome (Figures $6 \mathrm{a}$ and $6 \mathrm{~b}$ ) is understandable given the afore mentioned low number of transition offense situations that ended with a post-up maneuver. The same can be said for unsuccessful performances in using this movement (Figures 7a and $7 b)$.

\section{Research limitations}

The author of the paper is aware of limitations of this research, which are numerous. One of them is that the research could have being conducted on all teams competing in the EuroLeague and not just on two as in this case. Unfortunately, it was not possible at the time due to organizational reasons (data collection and processing).

Furthermore, only TP \& R/P and post-up maneuvers were analyzed in this study as two possible endings of transition offenses that should be expanded in future research, although these variables are certainly an important factor in transition offense and thus in success in basketball game.

Finally, it should be emphasized that the primary goal of the paper was to present the concept of an original research approach that could be applied in future researches of this type.

\section{CONCLUSION}

Transition pick \& roll/pop as well as an early pick in the transition is statistically significant as it is higher in the ZALG team because of a different concept and composition of the team since they 
played more transition game or early pick in transition.

Research has also found that these two teams differ significantly in unsuccessful transition P\&R/P where the ANA had statistically significant less mistakes compared to the ZALG. The assumption is that the ANA primarily played less transition P \& $R$ and transition post-up than the ZALG, and therefore they had less opportunity to make an error.

Analyzed two teams differ significantly in T P-up total, which primarily depends on the profile of players, but also on the general tendency that there were no more very dominant centers, so there was a lack of tendency to play post-up and in transition. Also, from the team profile it can be concluded that the ZALG had generally more players in post-up play than the ANA, and accordingly the team philosophy of the game is different. There were no more dominant centers as before and there were more polyvalent players, so it resulted in more switching's. It means that there was no longer a big advantage in the strength and height of the players, so there were no as many benefits as used to. The fourth significant difference between these two teams is in the variable \% TO, where the ZALG transition offense had more lost balls based on early pick and post up. It can be concluded that the ANA team did a better selection of realizations when they got into transition post up maneuver and the Zalgiris team insisted on a transition game at the cost of a mistake, so thus more turnovers occurred.

Comparisons between matches that ended in victory or defeat showed higher total number of occurrences of transition offenses in relation to defeats which is in line with previous scientific researches and practice. This tells us about its high representation and high percentage of success in matches of the highest quality and thus the distinction between winning and losing teams.

Furthermore, losing teams had a significantly lower frequency of overall use of $P \& R$ situations than the winning ones, which is interesting from the aspect of practice because it indicates the importance of practicing transition $P \& R$ in training and its application in matches. At the same time, it is necessary to emphasize and consider the quality of players that each team has in order for these actions to be successful because these situations largely determine success of the team in the match.

Winning teams also have a higher number of successful finishes in transition P\&R situations than losing teams which is understandable given that these are mostly simple finishes that often, among other things, demoralize opposing players.

Accordingly, defeated teams had a higher number of unsuccessful transition P\&R realizations (Figures $4 \mathrm{a}$ and $4 \mathrm{~b}$ ). When it comes to the frequency of the use of transition post-up maneuvers, it was noticed that there had been a slight difference between winning and losing teams in favor of winning teams, which can be explained in the somewhat less frequent use of this activity in elite basketball and because of slightly higher quality of centers when players play in the low or middle low post position.

Almost equal frequency of events between winning and losing teams in the use of a transition post-up maneuver that ended in a successful outcome is understandable given the afore mentioned low number of transition offense situations that ended in a post-up maneuver. The same can be said for unsuccessful performances in using this movement.

The transition offenses reveal new tactical system selection choices that coaches can use at different levels of competition as a potentially successful action strategy. To sum up, presented differences between two analyzed teams in $T P \& R$ and $T$ Post up teach us that the obtained differences are primarily conditioned by the selection of players that each team has and consequently the orientation of the tactical systems of the game that each team plays. In this way, it is difficult to say for sure whether differences in the application of the analyzed elements of the game are crucial for the position of two teams in the table. Therefore, the main difference comes from the philosophy of the coach and the very concept of the team or individual quality of players.

\section{REFERENCES}

1. Csataljay, G., O Donoghue, P., Hughes, M., Dancs, H.: (2009). Performance indicators that distinguish winning and losing teams in basketball. International Journal of Performance Analysis in Sport 9.1, 60-66.

2. Conte, D., Favero, T.G., Niederhausen, M., Capranica, L., Tessitore, A. (2017). Determinants of the effectiveness of fast break actions in elite and sub elite Italian men's basketball games. Bio Sport, 24(2) 177-183.

3. Dežman, B., Trninić. S., Dizdar, D. (2001). Expert Model of Decision-Making System for Efficient Orientation of Basketball Players to Positions and Roles in the Game - Empirical Verification. Collegium Antropologicum. 25, 1: $141-152$. 
4. Conte, D., Lukonaitiene, I. (2018). Scoring Strategies Differentiating Between Winning and Losing Teams During FIBA EuroBasket Women 2017. Sports, 6, 50.

5. Fotinakis, P., Karipidis, A., Taxildaris, K. (2002). Factors characterizing the transition game in European basketball. Journal of Human Movement Studies, 42, 305-316.

6. Garefis, A., Tsitskaris, G., Mexas, K., Kyriakou, D. (2007). Comparison of the effectiveness of fast breaks in two high level basketball championships. International Journal of Performance Analysis in Sport, Vol. 7, No. 3, Oct. 2007 , pp. 9-17 (9)

7. Sánchez-Delgado, G., Courel, J., Estévez-López, F., Ortega, E., Pińar, M.I., Cárdenas, D. (2012). Descriptive study of fastbreak motor variables at top level basketball. Comparative anlaysis between winners and losers. VII Congreso International de la Asociación Espańola de Ciencias del Deporte; Granada (Espańa) Nov/2012

8. Selmanovic, A., Skegro, D., Milanovic. D. (2015). Basic characteristics of offensive modalities in the EuroLeague and the NBA. University of Dubrovnik, Croatia, Acta Kinesiologica 9, 2: 83-87.

9. Trninić, S., Perica, A., Pavičić, L. (1994). Analiza stanja u košarkaškoj utakmici. Kineziologija, 26 (1-2): $27-32$.

10. Trninić, S., Dizdar, D. (2000). System of the Performance Evaluation Criteria Weighted per Positions in the Basketball Game. Collegium Antropologicum, 24, 1: 217-234.

11. Trninić, S., Trninić, M., Jelaska, I. (2010). Hierarchical Structuring of Knowledge in Basketball Game. Acta Kinesiologica, 4, 1: 37-44

12. Tsamourtzis, E., Karypidis, A., Athanasiou, N. (2005). Analysis of fast breaks in basketball. International Journal of Performance Analysis in Sport, 4 (2): 17-22.

Correspondence to:

Mario Jeličić 